\title{
Music and wine tasting: an experimental neuromarketing study
}

\author{
Liwei Hsu and Yen-jung Chen \\ National Kaohsiung University of Hospitality and Tourism, Kaohsiung, Taiwan
}

\begin{abstract}
Purpose - Music has a priming effect on product selection. The purpose of this paper is to extend the current understanding on this issue using an experimental design incorporating behavioural and brainwave data. Design/methodology/approach - An experiment with 40 participants was conducted to explore how and why wine tasting preferences would be primed by different genres of musical stimuli. Electroencephalographic measurement was adopted to measure participant brainwave activity in two experiments, each involving two rounds of wine tasting, and the treatment was administered between the two rounds.

Findings - Significant associations between the musical stimulus genre and participant change in wine selection were found, and the musical stimuli resulted in different brainwave activities because participant $\beta$ and $\gamma$ wave activities significantly differed in the first and second wine tasting rounds. Correlational analyses indicated that $\alpha, \beta$ and $\gamma$ wave activities generated by the musical stimuli were significantly but negatively correlated with $\alpha$ wave activity. $\alpha$ wave activity in the musical stimulus phases was significantly negatively correlated with $\beta$ wave activity in the second round of wine tasting, and the other associations were significant and positive.

Originality/value - This study highlighted the priming effect of musical stimuli in wine tasting. Empirical evidence derived from experimental research was analysed with behavioural and brainwave data. This study's original contribution is that it explored wine tasting preferences from a neuromarketing perspective. The results of this study can provide empirical evidence on how to effectively use music in marketing strategies.
\end{abstract}

Keywords Music, Neuromarketing, Priming effect, Wine selection

Paper type Research paper

\section{Introduction}

It has been stated that an individual's environmental sensory experience would prime the individual's response to stimuli (Simner et al., 2010). Numerous studies have examined the effect of music on affective, behavioural and temporal variables (Bhatti et al., 2016; Shih et al., 2009). Music is considered as the language of emotion and plays a vital role in social communication, further affecting behavioural patterns (Bhatti et al., 2016). Some types of music may reduce an individual's anxiety, whereas others may increase anxiety levels (Scheufele, 2000). The effect of music on consumer behaviour has been of great research interest, and it has been postulated that music would exert greater influence on sophisticated products such as luxury and technological goods. The concept of "musical fit" reflects the fact that consumer purchasing decisions would be influenced by how background music activates their superordinate knowledge structures (Yeoh and North, 2012).

(C) Liwei Hsu and Yen-jung Chen. Published by Emerald Publishing Limited. This article is published under the Creative Commons Attribution (CC BY 4.0) licence. Anyone may reproduce, distribute, translate and create derivative works of this article (for both commercial and non-commercial purposes), subject to full attribution to the original publication and authors. The full terms of this licence may be seen at http://creativecommons.org/licences/by/4.0/legalcode

This study is financially sponsored by the Ministry of Science and Technology, Taiwan (MOST 107 2511-H-328-001). Meanwhile, the authors would like to extend sincere gratitude and appreciation for all the suggestions raised by the editors and anonymous reviewers.
Music and wine tasting

Received 20 June 2019

Revised 16 July 2019

1 August 2019

Accepted 1 August 2019 
$\mathrm{BFJ}$

122,8

2726

Recent studies have further indicated the effect of music on one's dining experience (Carvalho et al., 2016; Spence et al., 2014; Wang et al., 2017; Wang and Spence, 2015, 2018). For example, North et al. (1999) and Wang and Spence (2018) reported that the level of matching between music and wine may significantly influence the tasting experience, i.e. music-taste congruency does play a vital role in one's intake of drink/food. They also called for more empirical evidence to examine the effect of music on food/drink tasting attributes.

Given the fact that over 70 per cent of purchasing decisions are made at the point of sale, marketers are striving to provide positive connection between consumers' emotion and their products (Horska et al., 2016). Particularly in wine business, consumers ordinarily select a bottle of wine for hedonistic reasons for special occasions instead of considering cost (Olsen et al., 2012). Any specific reason such as product category cannot fully explain how product selections are made (Bruwer et al., 2017); in fact, behavioural theory suggests that people tend to depend on their feelings when making decisions (Scorrano et al., 2018). Therefore, exploring hidden secrets related to one's emotion is of great value to wine marketing. In light of this, it has been asserted that specific music genres may be able to activate an individual's knowledge structure, which is considered to influence one's product choices, and food/drink products are no exception. Numerous studies (Biswas et al., 2018; Harrington et al., 2015; Jeon et al., 2016; Michel et al., 2017; North et al., 2016; Soh et al., 2015; Zellner et al., 2017) have investigated the effect of background music a restaurant plays on customer purchase intentions. For example, it has been found that background music with more low-pitch notes will relax consumers and promote healthy food sales, whilst high-pitch sounds will excite consumers and lead to unhealthy food choices (Biswas et al., 2018). In a similar vein, the experiment of Zellner et al. (2017) revealed that background music and diners' food selections were influenced by the country of origin of the background music; specifically, playing Spanish background music led more diners to order paella instead of Italian Parmesan cheese. Moreover, classical music might incur customers' intention to order expensive dishes and French music could lead to better sales in French wines. The positive relationship about the "match" of music genre and foods have been confirmed empirically (Shih et al., 2009) but specific explanations underpinning the influence of music on our decision is still underexplored (Bhatti et al., 2016). Moreover, it is to our best knowledge that pertinent phenomenon has not been extensively discussed through the lens of neuromarketing.

Neuromarketing is an emergent interdisciplinary field of study that integrates psychology, neuroscience, marketing and economics to understand and analyse consumer cognitive and emotional response to marketing stimuli (Lee et al., 2007; Malär et al., 2011; Sebastian, 2014). Rationale of neuromarketing lies on the postulation that understanding how consumers' brains perceive, process, think and react will make marketing strategies more effective (Horska et al., 2016). Before the advent of neuromarketing, the conventional ways of marketing research gradually showed their limits because reliability as well as validity of such studies depend greatly on the participants' willingness and competence to express their feedback towards marketing stimuli (Ariely and Berns, 2010). With the neuroscience method to reveal individual's brain activities, marketing scholars as well as practitioners will be able to extract valuable insight on consumers' subconscious responses to marketing stimuli (Morin, 2011).

Given the marked complexity of the human brain, neuromarketing research is at the embryonic stage (Morin, 2011). Interactions of neurons with electrochemical signals in the brain will generate electric and magnetic fields that can be picked up by electroencephalogram (EEG) to represent different signal patterns in terms of frequency and amplitude (Horska et al., 2016; Hossan and Chowdhury, 2016; Makada et al., 2016; Ramdinmawii and Mittal, 2017). The characteristics of brainwaves vary according to the state of individual activities and emotions. According to the frequency range, five bands 
$(\delta, \theta, \alpha, \beta$ and $\gamma)$ are usually considered in academic research and clinical practice (Ismail et al., 2016). Detailed descriptions on the five brainwaves and how they are interpreted in terms of an individual's state of mind are shown in Table I.

\section{Theoretical background: studies on the priming effect}

As McNamara (2005) coined the term priming as "an improvement in performance in a perceptual or cognitive task, relative to an appropriate baseline, produced by context or prior experience" (p. 3), priming can be used in knowledge activation to result to specific outcomes (Minton et al., 2017). The priming effect refers to a situation in which priming of an item or issue may influence people's judgement, which has been extensively discussed in the related research on cognitive media effect (Wang, 2007). As the tripartite model empirically validated by Breckler (1984), priming effects can be attributed to three aspects, namely, affective, behavioural and cognitive and this present study was designed to explore how the priming effect of musical stimuli influences consumer decisions on wine selection. Klauer and Musch (2003) further indicated that priming can be both affective and cognitive but that affective priming would be stronger. Minton et al. (2017) defined affective priming as the technique of using stimuli to influence an individual's affective response and cognitive priming is employed to change one's thoughts. Most stimuli for cognitive priming comprise words and thus cognitive priming is also known as semantic priming and is prevalently discussed by most marketing research.

A recent study suggested that unconscious affective priming is engendered by individual's automatic mechanism, whereas conscious affective priming is usually triggered cognitively ( $\mathrm{Lu}$ et al., 2018). People automatically and unconsciously tend to evaluate incoming stimuli as positive or negative (Kawakami and Miura, 2018). Behavioural priming effects refer to change in one's behaviour framed by the primed constructs, which reflects his/her responses to the perceived constructs (May and Irmak, 2018). Nevertheless, Mamalaki et al. (2017) stated that it remains unclear how music and its characteristics affect one's eating and drinking behaviours. This paper aimed to extend the current knowledge on this issue by exploring whether the priming effect of music would affect consumer wine selection. The aim of this study was to provide researchers and the food and beverage industry with insight on how priming with musical stimuli may influence consumer wine selection behaviour. Three research hypotheses are drawn to be examined by this study:

H1. Participant selection of wine change significantly after the presentation of the musical stimuli.

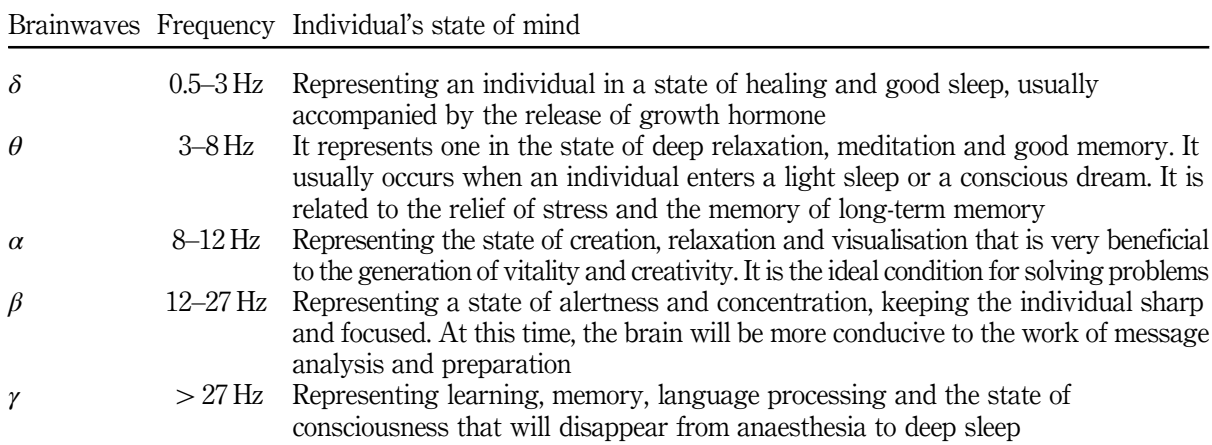

Source: Ismail et al. (2016)

Music and wine tasting
Table I. Description on brainwave and an individual's state of mind 
$\mathrm{BFJ}$

122,8

2728

H2. Participant brainwave activities would significantly differ between the two rounds of wine tasting.

H3. Brainwave activity whilst listening to the musical stimuli would be correlated with brainwave activity during the second round of wine tasting.

\section{Research methodology}

\subsection{Participants}

In this study, musical stimuli were used as control variables to explore the priming effect of music on participant preference of red wine. The experiment was performed on the campus of two universities in Southern Taiwan. As an experimental research, convenience sampling approach was adopted by this present study as many other experimental studies did, however, convenience sampling would potentially have biased samples (Boehnke et al., 2011). Therefore, in this present study, participant recruitment information was posted a social network platform, including clear guidelines on the participation requirements, i.e. having had no wine tasting experience. Through this way, the selection of research participants was not solely made by the researchers which made up the disadvantage of convenience sampling to the utmost. In total, 48 individuals responded to the recruitment post and 40 (18 male and 22 female) were invited to participate in this experiment, and the average age was 22.75 years (range, $21-35$ years; $\mathrm{SD}=2.10$ years). Among the excluded potential participants, three had food allergies, two had received training in catering services, one had participated in a Spanish study tour, one was left-handed and one had not reached the legal drinking age in Taiwan. All participants claimed that they had not travelled or lived in the related countries (i.e. France and Spain) to eliminate potential confounding of personal preference (Yeoh and North, 2012). All participants were naïve to EEG or other neuroscience-related experimental protocols. The participants further claimed no brain-related disorders, hearing impairment, or food allergies and they were all right-handed. All participants reported that they had not received training on wine tasting and that they had no profound knowledge of wine. They were not familiar with French chansons and Spanish songs (i.e. the musical stimuli of this experiment) or the French and Spanish languages. Furthermore, they did not have alcohol addiction. Importantly, they were not using any medication that would affect gustation. The participants were explicitly informed regarding the nature, procedures and scope of this study, and all participants provided informed consent prior to the onset of the experiment.

\subsection{Measurements and instrumentation}

Electroencephalogram (EEG) was used to measure brainwave activity, which has been extensively used in research and clinical practice to evaluate an individual's real-time emotional reactions towards specific stimuli (Palmiero and Piccardi, 2017; Wu and Sun, 2018), particularly that music perception and emotional processing are interweaved, which may lead to EEG power change (Lin et al., 2010). Furthermore, EEG is considered the optimal modality for recording human brainwave activity (Lokannavar et al., 2015). Neurosky Mindwave, a non-invasive instrument attached to the forehead and ear (referring to the Fp1 and A1 positions in the international 10-20 system), was used to collect brainwave data; Neurosky Mindwave has been previously used in marketing research (Goode and Iwasa-Madge, 2019) and its reliability has been confirmed by scholars such as Rogers et al. (2016). The EEG equipment used in this experiment can retrieve and record $\delta, \theta, \alpha, \beta$ and $\gamma$ brainwave activity simultaneously. Moreover, the accuracy and appropriateness of Neurosky Mindwave as a research instrument to detect brainwave activity has been previously confirmed (Sun, 2014). The fact that it is inconspicuous can also minimise the stress or distraction that may occur during brainwave data acquisition, thus 
more accurately reflecting participant brainwave activity (Rebolledo-Mendez et al., 2009). According to Straticiuc et al. (2016), the effect of music on an individual can be evaluated by measuring brain activity in the frontal lobe; thus, the brainwave activity collected by this research instrument should be appropriate for the purposes of this study.

\subsection{Experimental design}

The experiment was designed to create a real wine tasting experience whilst the participants received musical stimuli. The design of this experiment was in compliance with the ethical standards stated in the 2013 Declaration of Helsinki for studies on human subjects. After informed consent was obtained, the participants completed two experiments within an interval of one month. Except for the musical stimuli, the processes of these two experiments were approximately identical; the researcher team prepared two glasses of wine (French and Spanish) for participants to evaluate. The French wine was a 2015 Val De L'Ours and the Spanish wine was a 2015 Lobetla Tempranillo. Both these wines were rated as 3.3 on a scale from 0 to 5 by reviewers on vivino.com; meanwhile, the price of both wines was approximately $\$ 15$ because price is an important factor to consumers' wine choice (Escobar et al., 2018) and this variable was controlled by this study.

For each experiment, two rounds of tasting were conducted, and the treatment was administered between the two rounds of wine tasting. In each round of tasting, the participants were seated in a comfortable chair at a distance of approximately $65 \mathrm{~cm}$ in front of two glasses of wine in a sound attenuated and illuminated room. Both of these two glasses of wine were identical in terms of volume and colour; additionally, they were served in the same type of glass. The wine order was counterbalanced for all participants and in each round of wine tasting, the participants were served $30 \mathrm{ml}$ of French and Spanish red wine (the participants was free to drink any amount of the 30 served $\mathrm{ml}$.). The participants were requested to state their wine preference in a blind taste test; the researcher team recorded and analysed the results of their selection as well as their brainwave data. The musical stimuli used in this study were two French chansons, La Vie en Rose and J'attendrai, and two Spanish songs, La Paloma and Besame Mucho. The musical stimuli were presented before the second round of tasting. Afterwards, the second round of wine tasting and selection took place.

To minimise possible EEG artefacts, participants were instructed to minimise their body movement; meanwhile, they were also asked to relax and feel comfortable during the entire experiment (Thammasan et al., 2017). Moreover, in order to ensure the reliability, validity, objectivity and rigour of the research results, all participants listened to the same piece of classical music for $3 \mathrm{~min}$ before the first round of tasting. This was performed to reduce the effect of the external stimuli on the emotional state of the participants. Additionally, the participants were also required to drink $30 \mathrm{ml}$ of water for taste correction before each wine tasting. French and Spanish wines were placed in a random manner in front of each participant to eliminate the possible effect of position memory. Details of the experiment are presented by Figure 1.

\subsection{Statistical analyses}

The present research plans to use the following statistical techniques to analyse the collected data. Descriptive statistics including frequencies and percentage were used to depict the numbers of participants whose selections of wines before and after the treatment. Furthermore, the $\chi^{2}$ test was employed to explore the significance of participant wine selection change after the presentation of the musical stimuli. With respect to brainwave activity in this present study, brainwave data $(\delta, \theta, \alpha, \beta$ and $\gamma)$ were transformed to standardized percentages to be analysed and contrasted. According to Bishara and Hittner (2012), when the sample size is greater than 20, the data may be transformed to fit the normal distribution and be used for Pearson correlation analysis with low possibility of 
BFJ
122,8

\section{0}

Figure 1.

Experiment procedure

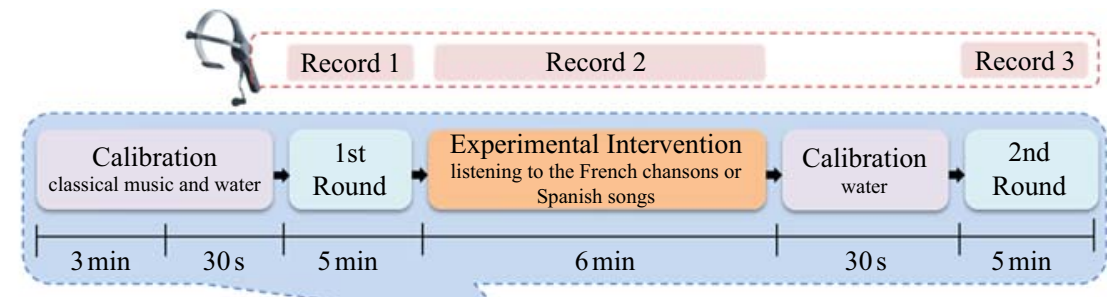

Experiment

\begin{tabular}{|c|c|} 
Preparation & Experiment \\
\hline $10 \mathrm{~min}$ & $20 \mathrm{~min}$
\end{tabular}

Type I and Type II errors. De Winter (2013) also indicated that paired sample $t$-tests can be used with small sample sizes. Therefore, in this study, the paired sample $t$-test a and Pearson's $r$ was used to investigate the correlation between brainwave activity during the presentation of the stimuli and brainwave activity during the second round of wine tasting Statistical analyses were performed with SPSS version 22.0 (IBM Corp., Armonk, NY).

\section{Results}

\subsection{Priming effect by music}

In order to elucidate whether the participant's choice of wine would be affected by the musical stimuli, the participants' subjective selection results were first reported as also shown in Table II.

As shown in Table II, in the French music phase, 50 per cent of the participants changed their selection from Spanish wine to French wine after listening to the two French chansons whilst 35 per cent of them changed from French wine to Spanish wine after having two Spanish songs as the musical stimuli. The $\chi^{2}$ test was further applied to analyse the data and revealed that in these two phases of musical stimuli, participant preferences were significantly different in three categories ("no change", "change from Spanish wine to French wine" and "change from French wine to Spanish wine"). It can be concluded from the results of the $\chi^{2}$ test of independence that the type of musical stimuli was significantly associated with participant change in wine preference $\left(\chi^{2}=16.54\right.$, Cramer's $V=0.46$, $p<0.001)$. Furthermore, comparing participant preference changes in the two rounds of wine tasting with the $\chi^{2}$ homogeneity test, it was shown that when the participants listened to the French chansons, the ratio of "change from Spanish wine to French wine" was significantly higher than the ratios of "no change" and "change from French wine to Spanish wine". Similarly, the ratio of "selecting French wine instead of Spanish wine" after listening to Spanish music was significantly higher than the ratio of "selecting from Spanish wine to French wine". Based on this result, the first research hypothesis cannot be rejected. The results of the $\chi^{2}$ analysis are shown in Table II.

Table II.

Descriptive statistics of participant selection of wine and $\chi^{2}$ test results of participant change of preference in wine selection

\begin{tabular}{|c|c|c|c|}
\hline Musical stimuli & No change & $\begin{array}{l}\text { Change from Spanish wine } \\
\text { to French wine }\end{array}$ & $\begin{array}{l}\text { Change from French wine } \\
\text { to Spanish wine }\end{array}$ \\
\hline $\begin{array}{l}\text { French chansons }(n=40) \\
\text { Spanish songs }(n=40)\end{array}$ & $\begin{array}{l}17(42.5 \%)^{\mathrm{a}} \\
21(52.5 \%)^{\mathrm{a}} \\
\gamma^{2}=16\end{array}$ & $\begin{array}{c}20(50.0 \%)^{\mathrm{b}} \\
5(12.5 \%)^{\mathrm{b}} \\
* \text { Cramer's } V=46^{* * *}\end{array}$ & $\begin{array}{c}3(7.5 \%)^{\mathrm{a}} \\
14(35.0 \%)^{\mathrm{a}}\end{array}$ \\
\hline
\end{tabular}

Notes: Each superscripted letter represents a subset of the wine selection category, with a line ratio of 0.05 . $* * * p<0.001$ 


\subsection{Brainwave analysis}

Further analyses of brainwave activity were conducted at different stages: whilst listening to music and during the wine tasting. Paired sample $t$-tests were used to statistically analyse the dominant brainwave activities during the two rounds of wine tasting. Specifically, the activity of three brainwaves ( $\alpha, \beta$ and $\gamma$ ) was compared during the first and second round of wine tasting; $\delta$ and $\theta$ waves were excluded because previous studies have indicated that they cannot be provoked when an individual is awake (Bernardi et al., 2019; Ismail et al., 2016; Nguyen et al., 2017; Zhong, 2015). The three brainwaves in the two experiments were recorded and analysed to examine if they would be significantly different. The results of the $t$-test analyses are reported in Table III.

The data reported in Table III show that there were significant differences in the dominant ratios of $\beta$ and $\gamma$ waves in the two rounds of wine tasting (in French musical stimuli, $t_{\beta}=2.75, p<0.01 ; t_{\gamma}=3.72, p<0.01$ whilst in Spanish musical stimuli, $t_{\beta}=3.69$, $\left.p<0.01 ; t_{\gamma}=-2.58, p<0.05\right) . \gamma$ wave activity was much more dominant in the second round of wine tasting after the participants listened to Spanish songs. Based on the results of the $t$-test, the second research hypothesis of this study is partially sustained.

Furthermore, Pearson product correlation analysis was carried out to examine whether participant brainwave activity during the presentation of the musical stimuli would be correlated with brainwave activity during the second round of wine tasting. Intriguing findings were produced by the correlation analyses; specifically, $\alpha$ and $\beta$ wave activities when the participants were exposed to the musical stimuli were found to be significantly correlated to the $\alpha, \beta$ and $\gamma$ wave activities during the second round of wine tasting. $\gamma$ wave activity in the experimental phase was found to be significantly correlated to $\alpha$ wave activity but non-significantly to $\beta$ and $\gamma$ wave activity in the second round of wine tasting. $\alpha$, $\beta$ and $\gamma$ wave activity when listening to music was significantly yet negatively correlated to $\alpha\left(r_{\alpha-\alpha}=-0.26, p<0.05 ; r_{\beta-\alpha}=-0.38, p<0.01 ; r_{\gamma-\alpha}=-0.56, p<0.001\right)$ wave activity in the second round of wine tasting. Furthermore, $\alpha$ wave activity during the musical stimulus presentation was also negatively correlated to $\beta$ wave activity during the second round of wine tasting $\left(r_{\alpha-\beta}=-0.62, p<0.001\right)$. Conversely, correlations between $\beta$ wave activity in the experiments and $\beta\left(r_{\beta-\beta}=0.43, p<0.001\right)$ as well as $\gamma\left(r_{\beta-\gamma}=0.39, p<0.001\right)$ wave activity during the second round of wine tasting were positive and significant. Meanwhile, $\alpha$ wave activity was significantly and positively correlated to $\gamma\left(r_{\alpha-\gamma}=0.62, p<0.001\right)$ wave activity during the presentation of the musical stimuli and the second round of wine tasting. Details of the results of this analysis are presented in Table IV.

\section{Discussion}

Thompson and Vourvachis (1995) suggested that taste was the most significant attribute correlated to consumer purchasing decisions of wines. For this reason, further exploration on participants' state of mind whilst tasting wines will be able to help us extend our current

\begin{tabular}{|c|c|c|c|c|c|c|c|}
\hline \multirow[b]{2}{*}{ Brainwaves } & \multirow[b]{2}{*}{ Round } & \multicolumn{3}{|c|}{ French } & \multicolumn{3}{|c|}{ Spanish } \\
\hline & & $M$ & $\mathrm{SD}$ & $t$ & $M$ & $\mathrm{SD}$ & $t$ \\
\hline \multirow[t]{2}{*}{$\alpha$} & 1st round of wine tasting & 23.62 & 8.87 & 0.10 & 20.51 & 6.19 & -1.37 \\
\hline & 2nd round of wine tasting & 23.43 & 4.92 & & 23.20 & 8.02 & \\
\hline \multirow[t]{2}{*}{$\beta$} & 1st round of wine tasting & 22.45 & 2.42 & $2.75^{* * *}$ & 22.54 & 7.30 & $3.69 * *$ \\
\hline & 2 nd round of wine tasting & 19.70 & 4.96 & & 15.70 & 5.15 & \\
\hline \multirow[t]{2}{*}{$\gamma$} & 1st round of wine tasting & 22.96 & 6.45 & $3.72^{* * *}$ & 23.08 & 5.80 & $-2.58^{*}$ \\
\hline & 2nd round of wine tasting & 20.72 & 3.81 & & 27.70 & 5.62 & \\
\hline
\end{tabular}

Notes: ${ }^{*} p<0.05 ; * * p<0.01$
Music and wine tasting

2731 
$\mathrm{BFJ}$ 122,8

2732

Table IV.

Correlations of brainwaves during the presentation of musical stimuli and during the second round of wine tasting $(n=80)$ understanding about consumers' brain activity. Priming effects can affect one's behaviour, and auditory stimuli are reportedly effective in inducing such effects (Hinojosa et al., 2009). Pellegrino et al. (2015) confirmed that consumer tastes would be affected by background sounds, but evidence on the priming effect generated by various genres of musical stimuli on one's wine tasting preferences remains scarce. The aim of this study was to bridge this gap in knowledge by investigating the priming effect of music on an individual's wine preferences. This study found that using French chansons as musical stimuli resulted in half (50 per cent) of the participants changing their selection from Spanish to French wine. Moreover, 35 per cent of the participants changed their preference from French to Spanish wine after listening to two Spanish songs presented as musical stimuli. The priming effect of musical stimuli was confirmed based on the statistically significant $\chi^{2}$ test of independence results. A prior study (Laran et al., 2010) confirmed that consumer behaviour will be primed by numerous marketing strategies; for example, brand names always have priming effects on consumers, whereas slogans have reverse priming effects. Instead of possible sources of priming effects used in marketing strategies such as brand names, slogans, brand representatives and pricing, the present study explored the priming effects of music stimuli on wine tasting. Compared to other factors, music is easier to manipulate and use at the point of sale (Jeon et al., 2016). The result of this experimental study offers an alternative approach to the marketing strategies of wine sales, i.e. applying the priming effects of music to consumers before their arrival to the sales point and expanding marketing interventions in terms of time and location as suggested by Biswas et al. (2018). However, the priming effect remains a debatable issue in psychology, and thus more evidence is needed (Minas and Dennis, 2019). Insightful information on the priming effect of musical stimuli can be drawn by analysing participant brainwave activities, and thus further comparisons on participant brainwave activities during the two rounds of wine tasting were conducted.

The paired sample $t$-test results incorporating the brainwave data also showed that significant differences existed between the dominant ratios of participant $\beta$ and $\gamma$ wave activities during the two rounds of wine tasting. The dominant ratios of $\alpha$ wave activity were not significantly different in this study because $\alpha$ wave activity does not appear to be influenced by emotion, which can be evoked by music (Lin et al., 2010). One explanation is that the musical stimuli successfully primed the participants' brain neuron activities. Music tempo does influence $\beta$ wave activity (Hurless et al., 2013), increasing with the tempo of musical stimuli (Tay and Ng, 2019), and the French chansons and Spanish songs selected for use in this study were slow in tempo, which would hamper the activity of $\beta$ waves. In this study, $\beta$ wave activities were the least remarkable in both the French and Spanish music phases. One possible reason may be that both the French chansons and Spanish songs relaxed the participants. $\gamma$ wave activity has been known to be "stimulus induced" (Muthukumaraswamy et al., 2010), which can always be triggered when one is required to make decisions, and the increased $\gamma$ band will appear when one is in ambiguous states (Castelhano et al., 2014). Therefore, it is plausible to assert that the participants were significantly influenced by the different musical stimuli, which resulted to their making decision on the second round of wine tasting to be a little more challenging

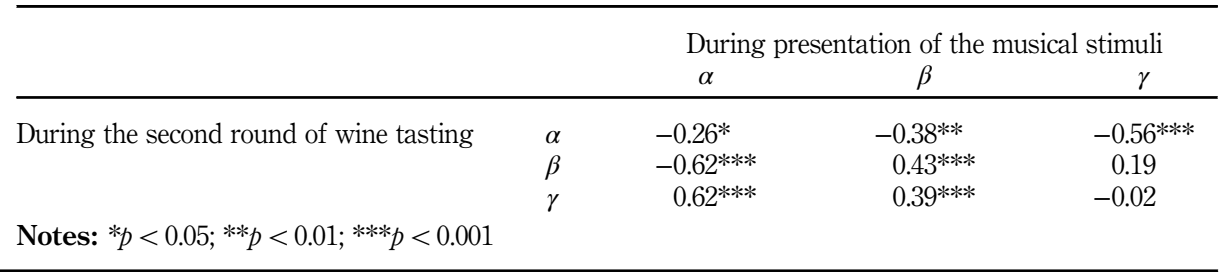


and eventually changed their choice of preferred wine. Future studies are encouraged to explore this issue in depth.

Additionally, $\gamma$ waves are also found to be related to memory (Ismail et al., 2016), which involve memory and information processing of new information (Straticiuc et al., 2016). French chansons even lowered the dominant ratio of $\gamma$ wave activity in the second round of wine tasting, which may be due to the specific French chansons used in this experiment. $\gamma$ wave activity appears to be associated with selective attention (Hughes, 2008) and the French chansons did not arouse participant attention, and thus, the dominant ratio of their $\gamma$ wave activity was lower in the second round of wine tasting. Spanish songs had the opposite effect, i.e. $\gamma$ wave activity increased after the participants listened to Spanish songs. Taking into account the participant decisions in the two rounds of wine tasting, the French chansons had a greater unconscious influence (priming) on participant selection in the second round of wine tasting.

Correlation analysis was conducted to examine the association between participant brainwaves during exposure to the musical stimuli and during the second round of wine tasting; significant correlations were discovered. Music has profound influence on an individual's state of mind (Hossan and Chowdhury, 2016; Makada et al., 2016; Ramdinmawii and Mittal, 2017; Wu and Sun, 2018) and it has been further stated that $\alpha$ synchronisation will occur if one listens to music that one is familiar with (Straticiuc et al., 2016), which was not the case in this study. Although participant $\alpha$ wave activity was significantly correlated to $\beta$ and $\gamma$ wave activities, the coefficients were negative. A possible reason may be the participants' unfamiliarity with the musical stimuli. This finding was in line with the results reported by Ramdinmawii and Mittal (2017) who found that $\alpha$ wave activity was rather less enhanced by pop music. Conversely, they also found that pop music may activate $\beta$ waves and the correlation analysis of this study indicated that participant $\beta$ wave oscillations in the musical stimulus phases had significant and positive correlations with $\beta$ and $\gamma$ wave activity during the second round of wine tasting, which supported the findings of Alvino et al. (2018).

\section{Conclusion, limitations and implications}

This present study adopted an experimental research design to examine the priming effect of music on participant wine tasting preference. In total, 40 participants participated in two procedurally similar experiments with a musical stimulus treatment (French chansons vs Spanish songs). Their choices on two rounds of wine tasting were recorded and analysed with the $\chi^{2}$ test, which reported a significant association between the genre of musical stimuli and the change in preference in the wine tastings. When also considering the brainwave data, it was found that the musical stimuli induced changes in brainwave activity. Participant $\beta$ and $\gamma$ wave activities were significantly different in the first and second wine tastings irrespective of whether the musical stimuli were French chansons or Spanish songs. Correlational analyses were conducted to examine the associations between participant $\alpha, \beta$ and $\gamma$ wave activities when listening to the musical stimuli and the second round of wine tasting. The results showed that $\alpha, \beta$ and $\gamma$ wave activity generated during the presentation of the musical stimuli had a significant but negative relationship with $\alpha$ wave activity in the second round of wine tasting. $\gamma$ wave activity generated during the presentation of the musical stimuli was not significantly associated with $\beta$ and $\gamma$ wave activities during the second round of wine tasting. Furthermore, $\alpha$ wave activity during the presentation of the musical stimuli had a significant and negative relationship with $\beta$ wave activity during the second round of wine tasting, and the other associations were significant and positive.

One limitation of this study is that unexamined factors may have affected the results. First, the underlying reason why the wine tasting would be primed by listening to music remains unclear. For example, sensory attribute of the wine may be one. The number of participants who changed their preference from Spanish to French wine was greater than

\author{
Music and \\ wine tasting
}

2733 
$\mathrm{BFJ}$

122,8

the opposite, and the potential reason may be that the two French chansons matched better the sensory attribute of the French wine, but Spanish songs did not have such a strong effect to match Spanish wine. Future studies are suggested to explore this issue with sensory analysis to provide us with empirical evidence from the perspective of sensory study.

Moreover, the participants of this study were randomly recruited volunteers who had the same cultural background; thus, the sample size was not sufficiently large and participant backgrounds were not diversified to generalise the results. Therefore, if more participants can be included in future studies, more insightful information may be elicited for practical and theoretical reference. Last but not least, we explored the priming effect of two particular music genres towards an individual's wine tasting; other potential effects such as types of music (classic, pop and rock music), volumes, as well as tempo of music were not taken into account; hence, the results of this study should be interpreted with caution. Future studies are advised to include these factors in their research design to provide research findings with greater generalisability.

\section{References}

Alvino, L., Constantinides, E. and Franco, M. (2018), "Towards a better understanding of consumer behavior: marginal utility as a parameter in neuromarketing research", International Journal of Marketing Studies, Vol. 10 No. 1, pp. 90-106.

Alvino, L., van der Lubbe, R.H. and Constantinides, E. (2018), "Investigating individual preferences and brain activity in a wine tasting experience: a neuromarketing approach", 2018 Global Marketing Conference at Tokyo, pp. 559-564.

Ariely, D. and Berns, G.S. (2010), "Neuromarketing: the hope and hype of neuroimaging in business", Nature Reviews Neuroscience, Vol. 11 No. 4, pp. 284-292.

Bernardi, G., Betta, M., Ricciardi, E., Pietrini, P., Tononi, G. and Siclari, F. (2019), "Regional delta waves in human rapid eye movement sleep", Journal of Neuroscience, Vol. 39 No. 14, pp. 2686-2697.

Bhatti, A.M., Majid, M., Anwar, S.M. and Khan, B. (2016), "Human emotion recognition and analysis in response to audio music using brain signals", Computers in Human Behavior, Vol. 65 No. 28, pp. 267-275.

Bishara, A.J. and Hittner, J.B. (2012), "Testing the significance of correlation with nonnormal data: comparison of Pearson, Spearman, transformation, and resampling approaches", Psychological Methods, Vol. 17 No. 3, pp. 399.

Biswas, D., Lund, K. and Szocs, C. (2018), "Sounds like a healthy retail atmospheric strategy: effects of ambient music and background noise on food sales", Journal of the Academy of Marketing Science, Vol. 47 No. 1, pp. 37-55.

Boehnke, K., Lietz, P., Schreier, M. and Wilhelm, A. (2011), "Sampling: the selection of cases for culturally comparative psychological research", in Matsumoto, D. and van de Vijver, F.J.R. (Eds), Culture and Psychology. Cross-Cultural Research Methods in Psychology, Cambridge University Press, New York, NY, pp. 101-129.

Breckler, S.J. (1984), "Empirical validation of affect, behavior, and cognition as distinct components of attitude", Journal of Personality and Social Psychology, Vol. 47 No. 6, pp. 1191-1205.

Bruwer, J., Chrysochou, P. and Lesschaeve, I. (2017), "Consumer involvement and knowledge influence on wine choice cue utilisation", British Food Journal, Vol. 119 No. 4, pp. 830-844.

Carvalho, F.R., Wang, Q.J., Van Ee, R. and Spence, C. (2016), "The influence of soundscapes on the perception and evaluation of beers", Food Quality and Preference, Vol. 52 No. 5, pp. 32-41.

Castelhano, J., Duarte, I.C., Wibral, M., Rodriguez, E. and Castelo-Branco, M. (2014), "The dual facet of gamma oscillations: separate visual and decision making circuits as revealed by simultaneous EEG/fMRI”, Human Brain Mapping, Vol. 35 No. 10, pp. 5219-35. 
De Winter, J.C. (2013), "Using the Student's $t$-test with extremely small sample sizes", Practical Assessment, Research \& Evaluation, Vol. 18 No. 10, pp. 1-10.

Escobar, C., Kallas, Z. and Gil, J. (2018), “Consumers' wine preferences in a changing scenario”, British Food Journal, Vol. 120 No. 1, pp. 18-32.

Goode, M.R. and Iwasa-Madge, D. (2019), "The numbing effect of mortality salience in consumer settings", Psychology \& Marketing, Vol. 36 No. 6, pp. 630-41.

Harrington, R.J., Ottenbacher, M.C. and Treuter, A. (2015), "The musicscape model: direct, mediating, and moderating effects in the casual restaurant experience", International Journal of Hospitality \& Tourism Administration, Vol. 16 No. 2, pp. 99-121.

Hinojosa, J.A., Carretié, L., Méndez-Bértolo, C., Miguez, A. and Pozo, M.A. (2009), “Arousal contributions to affective priming: electrophysiological correlates”, Emotion, Vol. 9 No. 2, pp. 164-71.

Horska, E., Bercik, J., Krasnodebski, A., Matysik-Pejas, R. and Bakayova, H. (2016), "Innovative approaches to examining consumer preferences when choosing wines", Agricultural Economics/ Zemedelska Ekonomika, Vol. 62 No. 3, pp. 124-133.

Hossan, A. and Chowdhury, A.M. (2016), "Real time EEG based automatic brainwave regulation by music", Informatics, Electronics and Vision (ICIEV), 2016 5th International Conference on Informatics, Electronics and Vision (ICIEV), May, pp. 780-784.

Hughes, J.R. (2008), "Gamma, fast, and ultrafast waves of the brain: their relationships with epilepsy and behavior", Epilepsy \& Behavior, Vol. 13 No. 1, pp. 25-31.

Hurless, N., Mekic, A., Peña, S., Humphries, E., Gentry, H. and Nichols, D. (2013), "Music genre preference and tempo alter alpha and beta waves in human non-musicians", Impulse, Vol. 22 No. 4, pp. 1-11.

Ismail, W.W., Hanif, M., Mohamed, S.B., Hamzah, N. and Rizman, Z.I. (2016), "Human emotion detection via brain waves study by using electroencephalogram (EEG)", International Journal on Advanced Science, Engineering and Information Technology, Vol. 6 No. 6, pp. 1005-1011.

Jeon, S., Park, C. and Yi, Y. (2016), "Co-creation of background music: a key to innovating coffee shop management”, International Journal of Hospitality Management, Vol. 58 No. 6, pp. 56-65.

Kawakami, N. and Miura, E. (2018), "Tracking hand movements captures the response dynamics of the evaluative priming effect", Cognition and Emotion, Vol. 33 No. 3, pp. 452-465.

Klauer, K.C. and Musch, J. (2003), "Affective priming: findings and theories", in Musch, J. and Klauer, K.C. (Eds), The Psychology of Evaluation: Affective Processes in Cognition and Emotion, Lawrence Erlbaum Associates Publishers, Mahwah, NJ, pp. 7-49.

Laran, J., Dalton, A.N. and Andrade, E.B. (2010), "The curious case of behavioral backlash: why brands produce priming effects and slogans produce reverse priming effects", Journal of Consumer Research, Vol. 37 No. 6, pp. 999-1014.

Lee, N., Broderick, A.J. and Chamberlain, L. (2007), "What is 'neuromarketing?? A discussion and agenda for future research", International Journal of Psychophysiology, Vol. 63 No. 2, pp. 199-204.

Lin, Y.P., Wang, C.H., Jung, T.P., Wu, T.L., Jeng, S.K., Duann, J.R. and Chen, J.H. (2010), “EEG-based emotion recognition in music listening", IEEE Transactions on Biomedical Engineering, Vol. 57 No. 7, pp. 1798-806.

Lokannavar, S., Lahane, P., Gangurde, A. and Chidre, P. (2015), "Emotion recognition using EEG signals”, Emotion, Vol. 4 No. 5, pp. 54-56.

Lu, Z., Lin, J. and Li, X. (2018), “An experimental study on relationship between subliminal emotion and implicit sequence learning: evidence from eye movements", International Journal of Psychological and Brain Sciences, Vol. 3 No. 1, pp. 1-6.

McNamara, T.P. (2005), Semantic Priming: Perspectives from Memory and Word Recognition, Psychology Press, New York, NY.

Makada, T., Ozair, D., Mohammed, M. and Abellanoza, C. (2016), "Enhancing memory retention by increasing alpha and decreasing beta brainwaves using music", Proceedings of the 9th ACM International Conference on Pervasive Technologies Related to Assistive Environments, June, p. 60. 
$\mathrm{BFJ}$

122,8

Malär, L., Krohmer, H., Hoyer, W.D. and Nyffenegger, B. (2011), "Emotional brand attachment and brand personality: the relative importance of the actual and the ideal self", Journal of Marketing, Vol. 75 No. 4, pp. 35-52.

Mamalaki, E., Zachari, K., Karfopoulou, E., Zervas, E. and Yannakoulia, M. (2017), "Presence of music while eating: effects on energy intake, eating rate and appetite sensations", Physiology \& Behavior, Vol. 168 No. 5, pp. 31-33.

May, F. and Irmak, C. (2018), "The effects of rarity on indulgent consumption: non-impulsives indulge when low frequency is salient", Journal of Consumer Research, Vol. 45 No. 2, pp. 383-402.

Michel, A., Baumann, C. and Gayer, L. (2017), "Thank you for the music-or not? The effects of in-store music in service settings", Journal of Retailing and Consumer Services, Vol. 36 No. 3, pp. 21-32.

Minas, R.K. and Dennis, A.R. (2019), "Visual background music: creativity support systems with priming", Journal of Management Information Systems, Vol. 36 No. 1, pp. 230-58.

Minton, E.A., Cornwell, T.B. and Kahle, L.R. (2017), "A theoretical review of consumer priming: prospective theory, retrospective theory, and the affective-behavioral-cognitive model", Journal of Consumer Behaviour, Vol. 16 No. 4, pp. 309-321.

Morin, C. (2011), "Neuromarketing: the new science of consumer behavior", Society, Vol. 48 No. 2, pp. 131-135.

Muthukumaraswamy, S.D., Singh, K.D., Swettenham, J.B. and Jones, D.K. (2010), "Visual gamma oscillations and evoked responses: variability, repeatability and structural MRI correlates", Neuroimage, Vol. 49 No. 4, pp. 3349-3357.

Nguyen, T., Ahn, S., Jang, H., Jun, S.C. and Kim, J.G. (2017), "Utilization of a combined EEG/NIRS system to predict driver drowsiness", Scientific Reports, Vol. 7 No. 43933, pp. 1-10.

North, A.C., Hargreaves, D.J. and McKendrick, J. (1999), "The influence of in-store music on wine selections", Journal of Applied Psychology, Vol. 84 No. 2, pp. 271-276.

North, A.C., Sheridan, L.P. and Areni, C.S. (2016), "Music congruity effects on product memory, perception, and choice", Journal of Retailing, Vol. 92 No. 1, pp. 83-95.

Olsen, J., Thach, L. and Hemphill, L. (2012), "The impact of environmental protection and hedonistic values on organic wine purchases in the US", International Journal of Wine Business Research, Vol. 24 No. 1, pp. 47-67.

Palmiero, M. and Piccardi, L. (2017), "Frontal EEG asymmetry of mood: a mini-review", Frontiers in Behavioral Neuroscience, Vol. 11 No. 224, pp. 1-8.

Pellegrino, R., Luckett, C.R., Shinn, S.E., Mayfield, S., Gude, K., Rhea, A. and Seo, H.S. (2015), "Effects of background sound on consumers' sensory discriminatory ability among foods”, Food Quality and Preference, Vol. 43 No. 9, pp. 71-78.

Ramdinmawii, E. and Mittal, V.K. (2017), "Effect of different music genre: attention vs. meditation", Affective Computing and Intelligent Interaction Workshops and Demos (ACIIW), 2017 Seventh International Conference on, October, pp. 135-140.

Rebolledo-Mendez, G., Dunwell, I., Martínez-Mirón, E.A., Vargas-Cerdán, M.D., De Freitas, S., Liarokapis, F. and García-Gaona, A.R. (2009), "Assessing NeuroSky's usability to detect attention levels in an assessment exercise", in International Conference on Human-Computer Interaction, July, pp. 149-158.

Rogers, J.M., Johnstone, S.J., Aminov, A., Donnelly, J. and Wilson, P.H. (2016), “Test-retest reliability of a single-channel, wireless EEG system”, International Journal of Psychophysiology, Vol. 106 No. 9, pp. 87-96.

Scheufele, P.M. (2000), "Effects of progressive relaxation and classical music on measurements of attention, relaxation, and stress responses", Journal of Behavioral Medicine, Vol. 23 No. 2, pp. 207-228.

Scorrano, P., Fait, M., Iaia, L. and Rosato, P. (2018), "The image attributes of a destination: an analysis of the wine tourists' perception”, EuroMed Journal of Business, Vol. 13 No. 3, pp. 335-350. 
Sebastian, V. (2014), "Neuromarketing and evaluation of cognitive and emotional responses of consumers to marketing stimuli”, Procedia-Social and Behavioral Sciences, Vol. 127 No. 148, pp. 753-757.

Shih, Y.N., Huang, R.H. and Chiang, H.S. (2009), "Correlation between work concentration level and background music: a pilot study", Work, Vol. 33 No. 3, pp. 329-333.

Simner, J., Cuskley, C. and Kirby, S. (2010), "What sound does that taste? Cross-modal mappings across gustation and audition", Perception, Vol. 39 No. 4, pp. 553-569.

Soh, K.L., Jayaraman, K., Choo, L.P. and Kiumarsi, S. (2015), "The impact of background music on the duration of consumer stay at stores: an empirical study in Malaysia", International Journal of Business and Society, Vol. 16 No. 2, pp. 247-260.

Spence, C., Velasco, C. and Knoeferle, K. (2014), "A large sample study on the influence of the multisensory environment on the wine drinking experience", Flavour, Vol. 3 No. 8.

Straticiuc, V., Nicolae, I. E., Strungaru, R., Vasile, T.M., Băjenaru, O.A. and Ungureanu, G.M. (2016), "A preliminary study on the effects of music on human brainwaves", Electronics, Computers and Artificial Intelligence (ECAI), 2016 8th International Conference, June, pp. 1-4.

Sun, J.C.Y. (2014), "Influence of polling technologies on student engagement: an analysis of student motivation, academic performance, and brainwave data", Computers \& Education, Vol. 72 No. 8, pp. 80-89.

Tay, R.Y.L. and Ng, B.C. (2019), "Effects of affective priming through music on the use of emotion words", PloS one, Vol. 14 No. 4, pp. 1-26.

Thammasan, N., Hagad, J.L., Fukui, K.I. and Numao, M. (2017), "Multimodal stability-sensitive emotion recognition based on brainwave and physiological signals", Affective Computing and Intelligent Interaction Workshops and Demos (ACIIW), 2017 Seventh International Conference on, October, pp. 44-49.

Thompson, K.E. and Vourvachis, A. (1995), "Social and attitudinal influences on the intention to drink wine", International Journal of Wine Marketing, Vol. 7 No. 2, pp. 35-45.

Wang, A. (2007), "Priming, framing, and position on corporate social responsibility", Journal of Public Relations Research, Vol. 19 No. 2, pp. 123-145.

Wang, Q. and Spence, C. (2015), "Assessing the effect of musical congruency on wine tasting in a live performance setting”, i-Perception, Vol. 6 No. 3, pp. 1-13.

Wang, Q. and Spence, C. (2018), "Assessing the influence of music on wine perception among wine professionals”, Food Science \& Mutrition, Vol. 6 No. 2, pp. 295-301.

Wang, Q.J., Keller, S. and Spence, C. (2017), "Sounds spicy: enhancing the evaluation of piquancy by means of a customised crossmodally congruent soundtrack", Food Quality and Preference, Vol. 58 No. 1, pp. 1-9.

$\mathrm{Wu}, \mathrm{X}$. and Sun, G. (2018), "Music-induced emotions and musical regulation and emotion improvement based on EEG technology", Neuro Quantology, Vol. 16 No. 6, pp. 379-384.

Yeoh, J.P. and North, A.C. (2012), "The effect of musical fit on consumers' preferences between competing alternate petrols", Psychology of Music, Vol. 40 No. 6, pp. 709-719.

Zellner, D., Geller, T., Lyons, S., Pyper, A. and Riaz, K. (2017), "Ethnic congruence of music and food affects food selection but not liking", Food Quality and Preference, Vol. 56 No. 14, pp. 126-129.

Zhong, G. (2015), "Analysis of healthy people's attention based on EEG spectrum”, Proceedings of the 2015 International Conference on Mechatronics, Electronic, Industrial and Control Engineering (MEIC-15), pp. 922-925.

\section{Corresponding author}

Liwei Hsu can be contacted at: liweihsu@mail.nkuht.edu.tw

For instructions on how to order reprints of this article, please visit our website:

www.emeraldgrouppublishing.com/licensing/reprints.htm

Or contact us for further details: permissions@emeraldinsight.com 